\title{
Addressing Inequities in Access to Health Products through the Use of Social Marketing, Community Mobilization, and Local Entrepreneurs in Rural Western Kenya
}

\author{
Julie R. Harris, ${ }^{1,2}$ Minal K. Patel, ${ }^{1,2}$ Patricia Juliao, , 2 Parminder S. Suchdev, ,, 3 \\ Laird J. Ruth, ${ }^{2,4}$ Vincent Were, ${ }^{5}$ Cliff Ochieng, ${ }^{5}$ Sitnah Hamidah Faith, ${ }^{5}$ Steven Kola, ${ }^{5}$ \\ Ronald Otieno, ${ }^{5}$ Ibrahim Sadumah, ${ }^{5}$ Alfredo Obure, ${ }^{5}$ and Robert Quick ${ }^{2}$ \\ ${ }^{1}$ Epidemic Intelligence Service, Office of Workforce and Career Development, Centers for Disease Control and Prevention, \\ Atlanta, GA 30333, USA \\ ${ }^{2}$ Enteric Diseases Epidemiology Branch, Centers for Disease Control and Prevention, Atlanta, GA 30333, USA \\ ${ }^{3}$ Department of Pediatrics, Emory University, Atlanta, GA 30322, USA \\ ${ }^{4}$ Nutrition Branch, Centers for Disease Control and Prevention, Atlanta, GA 30333, USA \\ ${ }^{5}$ Kenya Medical Research Institute, Kisumu 1570-50100, Kenya \\ Correspondence should be addressed to Julie R. Harris, ggt5@cdc.gov
}

Received 1 November 2011; Revised 21 March 2012; Accepted 25 March 2012

Academic Editor: Syed Masud Ahmed

Copyright ( 2012 Julie R. Harris et al. This is an open access article distributed under the Creative Commons Attribution License, which permits unrestricted use, distribution, and reproduction in any medium, provided the original work is properly cited.

While social marketing can increase uptake of health products in developing countries, providing equitable access is challenging. We conducted a 2-year evaluation of uptake of WaterGuard, insecticide-treated bednets (ITNs), and micronutrient Sprinkles in Western Kenya. Sixty villages were randomly assigned to intervention and comparison groups. Following a baseline survey (BL), a multifaceted intervention comprising social marketing of these products, home visits by product vendors from a local women's group (Safe Water and AIDS Project, or SWAP), product promotions, and modeling of water treatment and safe storage in was implemented in intervention villages. Comparison villages received only social marketing of WaterGuard and ITNs. We surveyed again at one year (FU1), implemented the intervention in comparison villages, and surveyed again at two years (FU2). At BL, $<3 \%$ of households had been visited by a SWAP vendor. At FU1, more intervention than comparison households had been visited by a SWAP vendor $(39 \%$ versus $9 \%, P<0.0001)$, and purchased WaterGuard $(14 \%$ versus $2 \%, P<0.0001)$, Sprinkles $(36 \%$ versus $6 \%, P<0.0001)$, or ITNs $(3 \%$ versus $1 \%, P<0.04)$ from that vendor. During FU2, $47 \%$ and $41 \%$ of original intervention and comparison households, respectively, reported ever receiving a SWAP vendor visit $(P=0.16)$; $>90 \%$ those reported ever purchasing a product from the vendor. WaterGuard $(P=0.02)$ and ITNs $(P=0.005)$ were purchased less frequently by lower-SES than higher-SES households; Sprinkles, the least expensive product, was purchased equally across all quintiles.

\section{Introduction}

In 2005, 1.4 billion people in the developing world lived on less than $\$ 1.25$ per day [1]. Children living in these regions also experienced the highest global burden of morbidity and mortality from acute respiratory infections, diarrhea, malaria, and malnutrition, and the poorest access to health services and improved water sources [2].

Provision of health products and services in resourcepoor countries is a major challenge to governments and aid organizations. Understanding the multiple competing needs of the poor, providing affordable products and services to meet those needs, and mobilizing resources for delivery of products and services, particularly to geographically remote areas, is challenging. Social marketing-broadly described as the combination of education to motivate healthy behaviors and the provision of attractively packaged, affordable products and services to low-income persons [3] -is one tool that has become widely used in recent years to promote health products such as condoms [4-6], insecticide-treated 
bednets (ITNs) [7-10], water treatment products, and other items [11] in developing countries. Although social marketing in developing countries has created product awareness through advertising and improved product access through widespread distribution, it has limitations. Among these are the requirement for individuals or families to have at least some disposable income, and the difficulty in ensuring availability of products to communities beyond the reach of existing commercial distribution networks $[3,12$, 13]. Consequently, access to socially marketed products is frequently uneven and inequitable $[9,14]$.

Nyanza Province, located in Western Kenya, has the worst mortality rates among children under 5 years of age in the country $(149 / 1,000$, compared with $74 / 1,000$ in Kenya overall) [15]. In Nyanza Province, the prevalence of anemia in children $<3$ years old was shown in a cross-sectional study to be 71-76\% [16]; the 2008-2009 Demographic and Health Survey [15] indicated that $24 \%$ of children under 5 years old had symptoms suggestive of malaria and 17\% had diarrhea in the preceding two weeks. Anemia, malaria, and diarrhea can be prevented by intake of iron-rich or iron-fortified food, ITNs, and household water chlorination, respectively.

A number of health products have been socially marketed in Kenya during the past decade. One Kenyan nongovernmental organization involved in the distribution of socially marketed products is the Safe Water and AIDS Project (SWAP). SWAP was designed to extend the reach and increase the impact of social marketing by mobilizing business-trained and microfinance-supported women's groups whose members act as promoters and vendors of health products in rural Kenyan communities, providing local awareness, health education, and access to these products.

The Nyando Integrated Child Health and Education Project (NICHE), which began in 2007 in Nyando District, a rural area of Nyanza Province, Kenya, aimed to evaluate the impact of SWAP's approach on the use and health impact of health products, particularly on children under 5 years old (2007). We present a report of SWAP's impact on equity of access to and use of water treatment products, a multiple micronutrient powder (Sprinkles), and ITNs.

\section{Methods}

2.1. Study Design. The NICHE project was a two-year, longitudinal study of 60 villages in rural western Kenya. At the time of selection, villages were randomized into intervention and comparison groups of 30 villages each. Awareness and household use of socially marketed health products were measured among study households in intervention and comparison villages at baseline $(\mathrm{BL})$, after which the intervention (see below) was implemented in intervention communities. All BL study households were visited every 2 weeks to monitor product purchases, product use, and household member morbidity for the duration of the study (these data will be presented elsewhere). At the end of the first year, a follow-up survey (FU1) was conducted in all 60 villages to evaluate overall changes in health product access, awareness, purchases, and use by study households. Following FU1, intervention activities were implemented in comparison villages. At the end of the second year, a second cross-sectional survey (FU2) was conducted. This study is registered at http://www.clinicaltrials.gov/, identifier NCT01088958.

2.1.1. Sampling and Enrollment Procedures. The study took place in Nyando Division, which has a population of approximately 80,000 persons in 15,000 households. Details of the formative research, study site and design are described elsewhere $[17,18]$. We used a two-stage cluster-sampling strategy to select the study population. In the first stage, we selected a random sample of 30 intervention and 30 comparison villages population proportional to size using 1999 census data. Intervention and comparison villages were selected from separate political divisions in an attempt to maintain geographical separation between study groups. In February 2007, we carried out a population census of the 60 study villages (Figure 1). In the second stage of sampling, we randomly selected 25 children aged 6 to 35 months from households in each intervention and comparison village. In villages with 25 or fewer children in the target age group, all children were sampled.

2.1.2. Baseline Survey (BL). At BL, trilingual (English, Kiswahili, and Dholuo) interviewers administered a questionnaire to one respondent identified as the main caretaker in each sampled household. The questionnaire included questions about household assets; knowledge, purchase, and use of certain health products; household health and hygiene practices. In addition, respondents were asked about home visits and purchases from product vendors ("SWAP vendors"; see below), and observations were made of bottles of WaterGuard in their homes. Following enrollment, the same person served as the household respondent over time, unless he or she became unavailable, at which point a permanent replacement respondent was selected from the household.

\subsubsection{Implementation of Product Promotion and Sales: Inter-} vention Communities. Before the study was initiated, project staff met with the Provincial and District Medical Officers, the District Commissioner, and local chiefs and assistant chiefs to obtain their approval and participation. After the baseline survey, women's groups participating in the Safe Water and AIDS Project (SWAP) were provided with basic health education and training on the proper use of health products, business practices, and microcredit. SWAP group members served their communities as educators, promoters, and vendors of health products, including the water treatment product WaterGuard, ITNs, and micronutrient Sprinkles. All products sold by SWAP except Sprinkles were available commercially in kiosks and markets in local villages and towns throughout the study area. WaterGuard and ITNs were socially marketed throughout Kenya using wall posters, paintings, and radio and print advertisements [19-21]. ITNs were distributed for free by the Kenyan government in 2006 during a national measles vaccination campaign (2007) and are now widely used throughout Kenya [22, 23]. Sprinkles had not been introduced in Kenya prior to this study and were only available from SWAP vendors. 


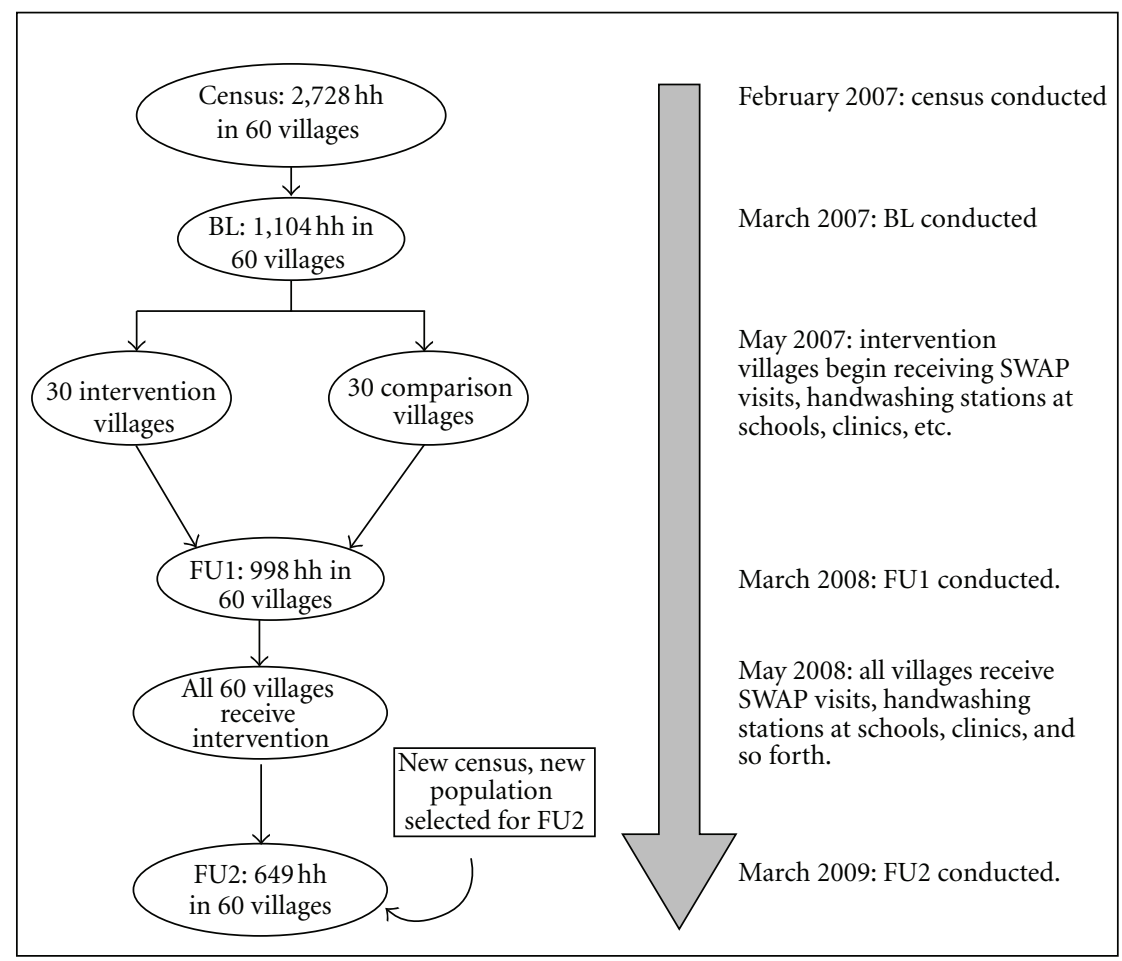

hh: households

Figure 1: Timeline of NICHE study, Nyando District, Kenya, 2007-2009.

SWAP vendors conducted product "launches" in villages to increase product awareness and then sold products door to door and, occasionally, in community settings (such as village meetings, kiosks, and churches). Launches were halfday events during which posters, promotional materials (such as branded plastic cups or calendars), educational leaflets, and product samples were given away, and a truck with a loudspeaker was used to broadcast information about the products. WaterGuard was advertised as a product to "make water safe"; ITNs were promoted as products to "prevent malaria," and Sprinkles was advertised as a product to "prevent low blood" (the local description of anemia) in children aged 6-59 months. A local mother with her child volunteered to be the "face" of Sprinkles, attending each launch during which the mother became known as "Mama Sprinkles." During the first year of the program, the development and activity of SWAP groups (product launches and door-to-door sales) occurred only in intervention villages; SWAP vendors were asked to limit the sale of their products to these villages (Figure 1). Products sold by SWAP were warehoused in the centrally located towns of Ahero and Awasi, in Nyando District. SWAP vendors traveled to these sites, purchased the products at wholesale prices, sold the products at retail prices, and kept the profit. Wholesale and retail product prices are shown in Table 1.

To increase exposure to water treatment and opportunities for good hygiene practices, and to provide a platform for teaching community members about hygiene, water stations for drinking water and hand washing, consisting of 60-liter plastic buckets with taps and lids, metal stands, and a starter
TABLE 1: Wholesale and retail prices of products (KSh) sold by SWAP vendors, NICHE study, Nyando District, Kenya, 2007-2009.

\begin{tabular}{lcc}
\hline & $\begin{array}{c}\text { Wholesale price to } \\
\text { vendors }\end{array}$ & $\begin{array}{c}\text { Retail price for } \\
\text { purchasers }\end{array}$ \\
\hline $\begin{array}{l}\text { WaterGuard } \\
\text { Insecticide-treated } \\
\text { bednets }\end{array}$ & $15 \mathrm{KSh}$ & $20 \mathrm{KSh}$ \\
Sprinkles & $40 \mathrm{KSh}$ & $50 \mathrm{KSh}$ \\
\hline
\end{tabular}

${ }^{*} 1 \mathrm{KSh} \sim 0.012$ USD.

supply of WaterGuard and soap, were installed in health facilities, primary schools, churches, and chiefs' homes in intervention villages by NICHE program staff. Program staff instructed persons receiving the water stations about proper use and continued to provide follow-up visits at least once per month throughout the study to reinforce their use. During the first year of the study, water stations were installed only at sites in the intervention villages.

2.1.4. Follow-Up Survey 1 (FU1). In March 2008, at the end of the first year of the study, we conducted a follow-up survey (FU1) in the project population. At FU1, household respondents were asked to answer the same questions asked at BL.

\subsubsection{Implementation of Product Promotion and Sales-} Comparison Communities. During year two, women's groups in comparison villages received training and water 
stations as described above; Sprinkles community launches were also conducted in these villages in July 2008 (Figure 1).

2.1.6. Follow-Up Survey 2 (FU2). Immediately before the 24month follow-up survey (FU2) in March 2009, a new census of all 60 villages was conducted, since all children from the originally selected households had aged out of the cohort (Figure 1). From this census, 12 children aged 6-35 months were randomly selected from each village to participate in FU2. At FU2, household respondents from both the original and the newly enrolled cohort were asked the same questions asked at BL and FU1.

2.1.7. Research Ethics. The protocol was approved by human subjects review committees at the Kenya Medical Research Institute (protocol 1176) and CDC (protocol 5039). Informed consent was obtained from all household respondents before enrollment.

2.2. Data Analysis. Data were collected using PDAs programmed with Visual CE software (Syware Inc, Cambridge, MA), downloaded to Microsoft Access 2000 databases, and analyzed using SAS 9.2 (SAS Institute, Cary, NC). Purchases of any product from vendors are reported only for persons receiving household visits from vendors; the denominator used for calculating utilization rates included the entire study population to enable evaluation of community-wide product uptake. Utilization rates were compared between different study groups using chi-square, Fisher's exact results, or Cochran-Armitage tests for trend, where appropriate. Data were analyzed after accounting for cluster sampling, with clusters at the village level. To classify respondents by socioeconomic status (SES), we used a principal component analysis (PCA) to group households into quintiles within the study population on the basis of household asset scores calculated by assigning values to housing materials and household possessions and summing them [24]. To determine the relative wealth of study households in comparison to the country as a whole, we also used summed asset scores to assign households to quintiles established for a national sample of Kenyan households [25]. To assess whether being observed modified product purchasing behavior ("Hawthorne effect"), FU2 data were grouped by whether the surveyed households had been visited before FU2 or for the first time during FU2, and product use rates were compared between the two groups.

\section{Results}

3.1. Baseline Enrollment. Of 2,728 households included in the original census, 1,104 households with at least one child aged 6 to 35 months were enrolled (Figure 1). At BL, 88\% of the NICHE study population was in the lowest SES quintile in Kenya (2007).

3.1.1. SWAP Activity. At BL, only $3 \%$ of respondents in intervention villages and $2 \%$ in comparison villages reported ever having received a household visit from a SWAP vendor $(P=$ 0.43) (Table 2). By FU1, 39\% of respondents in intervention villages and $9 \%$ of respondents in comparison villages reported ever having received a household visit by a SWAP vendor $(P<0.0001)$, and among these, a greater percentage of respondents from intervention than comparison households purchased a product from a SWAP vendor (95\% versus $88 \%, P=0.01)$. At FU2, $47 \%$ of respondents from the original intervention villages and $41 \%$ of respondents from the original comparison villages had received a household visit from a SWAP vendor $(P=0.16)$, and at least $90 \%$ from each group receiving a visit had purchased a product $(P=0.53)$.

Among intervention villages, there was substantial intervillage variation with regard to the proportion of NICHE respondents receiving a visit from a SWAP vendor at FU1 (median and mode proportion of respondents per village receiving a visit: 38\%, 38\%; range $8-83 \%$ ) and FU2 (median and mode proportion of respondents per village receiving a visit: $46 \%, 54 \%$; range $14-77 \%$ ); this was not associated with distance of the village from the SWAP vendor product purchasing center (data not shown).

At BL, similar percentages of respondents in intervention and comparison households reported ever purchasing WaterGuard ( $2 \%$ versus $1 \%$ ), ITNs $(<1 \%$ versus $0 \%)$, or Sprinkles (0\% versus $0 \%)$ from SWAP vendors (Table 2$)$. At FU1, greater proportions of respondents from intervention households than comparison households who received SWAP vendor visits reported purchasing WaterGuard (14\% versus $2 \%, P<0.0001$ ), ITNs ( $3 \%$ versus $1 \%, P<0.04$ ), and Sprinkles $(36 \%$ versus $6 \%, P<0.0001)$ from SWAP vendors. At FU2, the percentages of respondents from both intervention and comparison households that reported purchasing WaterGuard (27\% versus $21 \%$ ), ITNs ( $5 \%$ versus $5 \%$ ), and Sprinkles (39\% versus 33\%) from SWAP vendors were not significantly different.

3.2. WaterGuard Purchases from SWAP Vendors. At BL, similar proportions of intervention and comparison households (23\% each) were observed to have WaterGuard at home; however, at FU1, more intervention households (33\%) than comparison households (23\%) were observed to have a bottle of WaterGuard at home $(P<0.001)$ (Table 3$)$. By FU2, the proportion of intervention (55\%) and comparison (48\%) households with WaterGuard present had increased significantly from BL and FU1, although there were not significant differences between the two household groups at FU2.

Among households observed to have WaterGuard present at BL, no significant differences existed between intervention (7\%) and comparison (14\%) households with respect to whether the respondent reported that it was purchased from a SWAP vendor (Table 3); however, at FU1, a significantly greater proportion of respondents from intervention households (48\%) than comparison household (7\%) with WaterGuard present reported purchasing it from a SWAP vendor $(P<0.0001)$ (Table 3$)$. By FU2, these differences were no longer significant: (48\% versus $37 \% ; P=$ $0.19)$.

3.3. SES Analysis. The likelihood of a project household having received a home visit from a SWAP vendor, having made any purchase from a SWAP vendor, or having purchased 


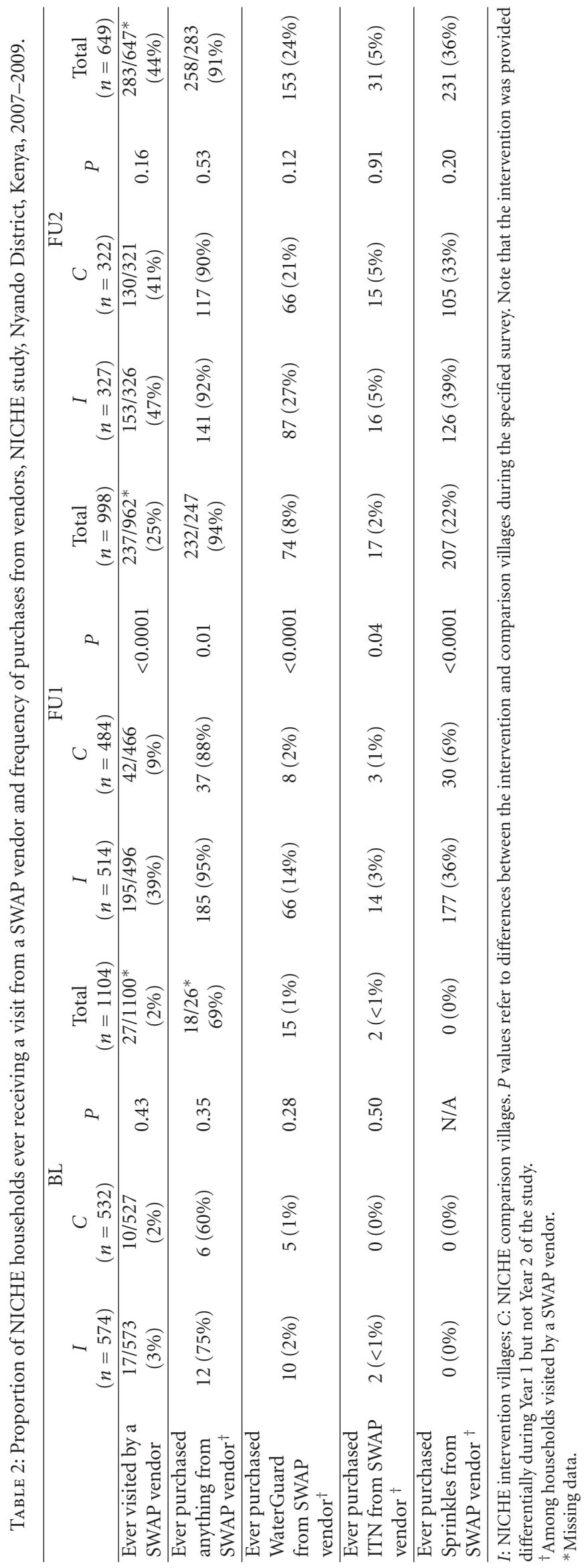


TABle 3: Presence of WaterGuard and sources of WaterGuard in intervention and comparison households with children in NICHE study, Nyando District, Kenya, 2007-2009.

\begin{tabular}{|c|c|c|c|c|c|c|c|c|c|}
\hline & \multicolumn{3}{|c|}{$\mathrm{BL}$} & \multicolumn{3}{|c|}{ FU1 } & \multicolumn{3}{|c|}{ FU2 } \\
\hline & $I$ & C & Total & $I$ & C & Total & $I$ & C & Total \\
\hline $\begin{array}{l}\text { Households with } \\
\text { WaterGuard present }\end{array}$ & $\begin{array}{c}130 / 574 \\
(23 \%)\end{array}$ & $\begin{array}{c}122 / 532 \\
(23 \%)\end{array}$ & $\begin{array}{l}252 / 1104 \\
(23 \%)\end{array}$ & $\begin{array}{c}166 / 497 \\
(33 \%)\end{array}$ & $\begin{array}{c}107 / 467 \\
(23 \%)\end{array}$ & $\begin{array}{l}273 / 964 \\
(28 \%)^{\dagger}\end{array}$ & $\begin{array}{c}179 / 327 \\
(55 \%)\end{array}$ & $\begin{array}{c}153 / 322 \\
(48 \%)\end{array}$ & $\begin{array}{c}332 / 649 \\
(51 \%)\end{array}$ \\
\hline $\begin{array}{l}\text { Purchased current } \\
\text { bottle from SWAP } \\
\text { vendor (at home visit } \\
\text { or otherwise) }\end{array}$ & $\begin{array}{l}9 / 130 \\
(7 \%)\end{array}$ & $\begin{array}{l}17 / 122 \\
(14 \%)\end{array}$ & $\begin{array}{l}26 / 252 \\
(10 \%)\end{array}$ & $\begin{array}{c}80 / 166 \\
(48 \%)\end{array}$ & $8 / 107(7 \%)$ & $\begin{array}{c}88 / 273^{\dagger} \\
(32 \%)\end{array}$ & $\begin{array}{c}74 / 155^{*} \\
(48 \%)\end{array}$ & $\begin{array}{c}52 / 139 * \\
(37 \%)\end{array}$ & $\begin{array}{c}126 / 294^{*} \\
(43 \%)\end{array}$ \\
\hline
\end{tabular}

${ }^{*}$ Missing responses.

${ }^{\dagger} P<0.001$ for differences between comparison and intervention groups. No other comparisons were significant at a $P<0.05$ level.

TABLE 4: Proportion of NICHE respondents ever receiving a household visit from a SWAP vendor, and frequency of purchases from vendors at FU2, by socioeconomic quintile, Nyando District, Kenya, 2007-2009. Q0: poorest quintile; Q4: least poor quintile.

\begin{tabular}{|c|c|c|c|c|c|c|}
\hline & $\mathrm{Q} 1(n=130)$ & $\mathrm{Q} 2(n=144)$ & $\mathrm{Q} 3(n=112)$ & $\mathrm{Q} 4(n=130)$ & Q5 $(n=128)$ & $\begin{array}{c}P(\text { Cochran- } \\
\text { Armitage test for } \\
\text { trend })\end{array}$ \\
\hline $\begin{array}{l}\text { Visited by a SWAP vendor? } \\
(n=644)\end{array}$ & $52(40 \%)$ & $66(46 \%)$ & $43(39 \%)$ & $69(53 \%)$ & $51(40 \%)$ & 0.62 \\
\hline $\begin{array}{l}\text { Purchased anything from a } \\
\text { SWAP vendor? }(n=281)^{\dagger}\end{array}$ & $44(85 \%)$ & $60(91 \%)$ & $42(98 \%)$ & $63(91 \%)$ & $47(92 \%)$ & 0.22 \\
\hline $\begin{array}{l}\text { Purchased WaterGuard } \\
(n=644)^{¥}\end{array}$ & $21(16 \%)$ & $32(22 \%)$ & $26(23 \%)$ & $41(32 \%)$ & $33(26 \%)$ & 0.02 \\
\hline $\begin{array}{l}\text { Purchased ITNs } \\
(n=644)^{¥}\end{array}$ & $2(2 \%)$ & $6(4 \%)$ & $3(3 \%)$ & $11(8 \%)$ & $9(7 \%)$ & 0.005 \\
\hline $\begin{array}{l}\text { Purchased Sprinkles } \\
(n=644)^{¥}\end{array}$ & $40(31 \%)$ & $54(38 \%)$ & $36(32 \%)$ & $59(45 \%)$ & $40(31 \%)$ & 0.51 \\
\hline
\end{tabular}

${ }^{\dagger}$ Among households visited by a SWAP vendor.

$¥$ Among all households in quintile.

Sprinkles was similar across all five socioeconomic quintiles (Table 4). However, households in wealthier quintiles were more likely than households in poorer quintiles to purchase WaterGuard $(P=0.02)$ and ITNs $(P=0.005$ [Table 4$])$.

3.4. Hawthorne Effect. From 810 households randomly selected during the new census conducted before FU2, we enrolled 649 households with 708 children aged 6-35 months. Among these 649 households, 372 (58\%) had not previously participated in the NICHE study (new participants) and 264 (41\%) had participated and received biweekly household visits throughout the two years of the study (twoyear participants). We excluded $13(2 \%)$ respondents, 11 of whom had previously dropped out of the study and $2(<1 \%)$ who did not complete the FU2 survey. Among two-year participants, 130 (49\%) reported ever having been visited by a SWAP vendor, compared with 146 (39\%) new participants $(P=0.02) ; 121(93 \%)$ of 130 two-year participants and $132(90 \%)$ of 146 new participants reported ever having purchased an item from a SWAP vendor $(P=0.40)$. After controlling for the occurrence of household SWAP vendor visits, a higher percentage of two-year participants than new participants reported purchasing an ITN (16\% versus $7 \%$, $P=0.04)$. There were no statistically significant differences between two-year participants and new participants in the purchase of Sprinkles (90\% versus $89 \%, P=0.69$ ) or Waterguard ( $61 \%$ versus $57 \%, P=0.56)$.

\section{Discussion}

In this study, we found that among persons in very low-income, rural households in Kenya, a multifaceted intervention that combined social marketing, community mobilization, and household product sales by local vendors increased both access to and purchase of proven health technologies, compared with social marketing alone. At baseline, all study households had little or no exposure to SWAP; after the first year of the intervention, households in intervention villages showed higher levels of exposure to and product purchasing from SWAP vendors compared with the comparison group. During the second year in which all study households and communities were exposed to the intervention, the comparison households "caught up" to the intervention households in reported product exposure and purchasing, with no measurable differences between the original intervention and comparison groups by the end of the second year. Household visits by SWAP vendors were equitably distributed across SES quintiles, although higherpriced items (WaterGuard and ITNs) were more likely to be purchased by respondents in higher wealth quintiles than 
lower wealth quintiles. Sprinkles, a nutritional supplement, appeared to be within the financial means of all groups, as evidenced by the similar rates of purchase across SES quintiles and the fact that Sprinkles was the most frequently tried product. These findings demonstrate that this type of intervention can be effective at both increasing access to and purchases of much-needed health products among the rural poor.

Several features of the intervention explain its effectiveness. First, the high level of community engagement required by the intervention likely contributed to increased exposure to products and sales. Second, the intervention was implemented at multiple levels of influence [26], including district and provincial governments, through mass media; local chiefs, religious leaders, school teachers, and health care providers; local village residents (i.e., SWAP group members). This approach created multiple opportunities for reinforcement of health messaging, provided many opportunities for product purchase, and enabled community members to view modeling of healthy behaviors. Third, using local residents as the "faces" of the health products and involving them in the design and execution of product promotions in the communities took advantage of preexisting relationships between vendors and purchasers, which might have facilitated sales. Finally, the use of home visits as a product delivery mechanism was well accepted by the population, as demonstrated by the finding that over $80 \%$ of community members receiving visits from SWAP vendors purchased something from the vendors at FU1 and FU2.

Although we collected "ever-visit" and "ever-purchase" data in each village with regard to household SWAP visits and products, respectively, we tracked neither individual vendor sales nor the frequency of SWAP visits to individual NICHE study participants' homes; thus, it is not known how variable the frequency of individual vendor visits were at NICHE participants' homes or between intervention villages. We found substantial variation between intervention villages in the proportions of residents ever receiving a visit from a SWAP vendor and can hypothesize that variation existed similarly in terms of how frequently different vendors sold SWAP products door to door; this likely would have influenced both individual NICHE participant and intervillage purchasing frequencies. Reasons for these variations might relate to mitigating social, economic, or political factors taking place during that time period. Focus group discussions with the SWAP vendors about sales of Sprinkles [18] demonstrated that several factors affected the ebb and flow of sales, including promotions intended to boost sales, vendor incentives, stockouts of Sprinkles, and postelection violence in Western Kenya during 2007-2008. In addition, the two centers for the vendor purchase of wholesale health products were located in two distinct areas of Kisumu (Awasi and Ahero), which may not have been equally accessible to all vendors. Sprinkles sales were shown to generally be inversely related to the distance from the SWAP distribution center to the village [18]. Some of these factors undoubtedly influenced sales of all products, while others influenced sales of only certain products. Although we did not track the reported use of all health products sold by SWAP, many products (not only the ones discussed here) were sold by the vendors, and thus their livelihoods were not dependent on single or a small number of products. Individual stockouts were unlikely to affect SWAP vendor activity as much as accessibility of the wholesale centers and political instability that made travel unsafe during certain periods. However, locations of wholesale centers, vendor and consumer incentives, and stockouts are modifiable factors; future implementations of this type of intervention may be able to be improved upon, to minimize the negative effects of these factors.

Study findings are unclear regarding whether a Hawthorne effect (the presence of observers influencing study results) took place among households that were visited regularly by study personnel for two years. Among study participants who were visited biweekly for two years (and therefore among whom a Hawthorne effect would be more likely), sales of ITNs were higher than among households newly enrolled for FU2, but sales of WaterGuard and Sprinkles were similar in the two groups. Repeated messaging is known to positively affect behaviors and uptake of new products, [27] and could explain study results.

With the exception of Sprinkles, uptake of health products by the poorest households remained a challenge for the SWAP vendors. This group is typically the most difficult to reach with any intervention [28], and additional efforts may be needed to promote intervention uptake in general, and among the poorest in particular. Targeted efforts focused on these groups may boost accessibility and sales. Parker et al. demonstrated that clinic-based education about water treatment at a maternal and child health clinic in western Kenya resulted in increases in reported purchases of water treatment products [29]; however, women participating in this study were unlikely to have been the poorest group, as many had businesses or salaried jobs. Briere et al. demonstrated that the bundling of immunizations and free hygiene interventions improved hygiene practices without adversely affecting immunizations [30]. Similarly, another study reported that including free hygiene kits as part of antenatal services in Malawi, in the context of a media campaign to support use of water treatment products, led to sustained increases in water treatment and handwashing knowledge, even among the very poor [31]. Free mass distribution has been shown to be the most effective method of decreasing inequities in distribution with other health interventions, such as ITNs [23, 32-34]; however, this approach is commonly criticized as it requires no "buy-in" from the recipients and thus may result in less value being place on the service or product. Although removal of all disparities with regard to access to health interventions may not be possible, continued investigation of combined approaches is critical to determining methods that are both cost-effective and disparity reducing.

Our study had several limitations: first, the data originated from one division in one district in Kenya and were therefore not necessarily representative of either Nyanza Province or Kenya as a whole. Second, because households were added at FU1 and a new population was selected at FU2 (albeit from the same villages), data from FU2 include 
responses from at least some new respondents and are therefore not directly linked to the baseline population. Finally, SES in African communities is not always reflected in household possessions and could be dependent on support from a relative or extended family [35]; therefore our assessment of household SES may have been inaccurate.

In summary, a combined intervention that augmented social marketing with product promotion at multiple levels of influence, community mobilization, and use of local self-help groups to market and sell products successfully increased product awareness, access, and use among a rural Kenyan population. Strategies utilizing multiple implementation approaches, multiple price points, and multiple levels of influence are a promising approach to increasing access to health interventions among the populations who need them most.

\section{Conflict of Interests}

The authors have no conflict of interests to declare.

\section{Authors' Contribution}

R. Quick, P. Suchdev, and P. Juliao conceived the study; they, L. Ruth and A. Obure were involved in study design. A. Obure, C. Ochieng, L. Ruth, V. Were, S. H. Faith, S. Kola, R. Otieno, and I. Sadumah were involved in study design and execution. J. Harris, M. k. Patel, and V. Were analyzed and interpreted the data. J. Harris and R. Quick drafted the paper. All authors provided critical review of the paper.

\section{Acknowledgments}

This paper is dedicated to the memory of Alfredo FXO Obure (1976-2009). The authors wish to thank the NICHE study enumerators, the residents of the villages who participated and supported the NICHE project, and staff of SWAP, without whom this study would not have been possible. This work was supported by the Centers for Disease Control and Prevention, Global Alliance for Improved Nutrition (GAIN), and the Global Bureau of the US Agency for International Development.

\section{References}

[1] S. Chen and M. Ravallion, "Developing world is poorer than we thought, but no less successful in the fight against poverty," World bank Policy Research Working Paper Series, 2008, http://ssrn.com/abstract=1259575.

[2] WHO, "World Health Statistics 2009," 2009, http://www.who .int/whosis/whostat/EN_WHS09_Full.pdf.

[3] PSI, "What is social marketing?" 2006, http://www.psi.org/ resources/research-metrics/publications/social-marketing-research-series/what-social-marketing-0.

[4] D. Meekers, R. Van Rossem, M. Silva, and A. Koleros, "The reach and effect of radio communication campaigns on condom use in Malawi," Studies in Family Planning, vol. 38, no. 2, pp. 113-120, 2007.

[5] R. Van Rossem and D. Meekers, "The reach and impact of social marketing and reproductive health communication campaigns in Zambia," BMC Public Health, vol. 7, article no. 352, 2007.

[6] M. Versteeg and M. Murray, "Condom use as part of the wider HIV prevention strategy: experiences from communities in the North West Province, South Africa," Sahara J, vol. 5, no. 2, pp. 83-93, 2008.

[7] D. P. Mathanga, C. H. Campbell, T. E. Taylor, R. Barlow, and M. L. Wilson, "Socially marketed insecticide-treated nets effectively reduce Plasmodium infection and anaemia among children in urban Malawi," Tropical Medicine and International Health, vol. 11, no. 9, pp. 1367-1374, 2006.

[8] S. Agha, R. Van Rossem, G. Stallworthy, and T. Kusanthan, "The impact of a hybrid social marketing intervention on inequities in access, ownership and use of insecticide-treated nets," Malaria Journal, vol. 6, article no. 13, 2007.

[9] A. M. Noor, A. A. Amin, W. S. Akhwale, and R. W. Snow, "Increasing coverage and decreasing inequity in insecticidetreated bed net use among rural Kenyan children," PLoS Medicine, vol. 4, no. 8, article e255, pp. 1341-1348, 2007.

[10] J. Bernard, G. Mtove, R. Mandike, F. Mtei, C. Maxwell, and H. Reyburn, "Equity and coverage of insecticide-treated bed nets in an area of intense transmission of Plasmodium falciparum in Tanzania," Malaria Journal, vol. 8, no. 1, article no. 65, 2009.

[11] W. D. Evans, J. Blitstein, J. C. Hersey, J. Renaud, and A. L. Yaroch, "Systematic review of public health branding," Journal of Health Communication, vol. 13, no. 8, pp. 721-741, 2008.

[12] R. Kyama and D. G. McNeil, "Distribution of nets splits malaria fighters,” New York Times, 2007.

[13] A. Teklehaimanot, J. D. Sachs, and C. Curtis, "Malaria control needs mass distribution of insecticidal bednets," Lancet, vol. 369, no. 9580, pp. 2143-2146, 2007.

[14] L. J. Stockman, T. K. Fischer, M. Deming et al., "Point-of-use water treatment and use among mothers in Malawi," Emerging Infectious Diseases, vol. 13, no. 7, pp. 1077-1080, 2007.

[15] Kenya National Bureau of Statistics, "N., Kenya and MEASURE DHS, ICF Macro, Calverton, Maryland, USA," Kenya: DHS, 2008-09, Final Report, 2009.

[16] M. R. Desai, D. J. Terlouw, A. M. Kwena et al., "Factors associated with hemoglobin concentrations in pre-school children in western Kenya: cross-sectional studies," American Journal of Tropical Medicine and Hygiene, vol. 72, no. 1, pp. 47-59, 2005.

[17] M. E. D. Jefferds, L. Ogange, M. Owuor et al., "Formative research exploring acceptability, utilization, and promotion in order to develop a micronutrient powder (Sprinkles) intervention among Luo families in western Kenya," Food and Nutrition Bulletin, vol. 31, no. 2, supplement, pp. S179-S185, 2010.

[18] P. S. Suchdev, L. Ruth, A. Obure et al., "Monitoring the marketing, distribution, and use of Sprinkles micronutrient powders in rural western Kenya," Food and Nutrition Bulletin, vol. 31, no. 2, supplement, pp. S168-S178, 2010.

[19] M. C. Freeman, R. E. Quick, D. P. Abbott, P. Ogutu, and R. Rheingans, "Increasing equity of access to point-of-use water treatment products through social marketing and entrepreneurship: a case study in western Kenya," Journal of Water and Health, vol. 7, no. 3, pp. 527-534, 2009.

[20] P. Makutsa, K. Nzaku, P. Ogutu et al., "Challenges in implementing a point-of-use water quality intervention in rural Kenya," American Journal of Public Health, vol. 91, no. 10, pp. 1571-1573, 2001.

[21] R. Quick, "Changing community behaviour: experience from three African countries," International Journal of Environmental Health Research, vol. 13, supplement 1, pp. S115-S121, 2003. 
[22] G. W. Fegan, A. M. Noor, W. S. Akhwale, S. Cousens, and R. W. Snow, "Effect of expanded insecticide-treated bednet coverage on child survival in rural Kenya: a longitudinal study," Lancet, vol. 370, no. 9592, pp. 1035-1039, 2007.

[23] A. M. Noor, J. J. Mutheu, A. J. Tatem, S. I. Hay, and R. W. Snow, "Insecticide-treated net coverage in Africa: mapping progress in 2000-07," The Lancet, vol. 373, no. 9657, pp. 58-67, 2009.

[24] D. Filmer and L. H. Pritchett, "Estimating wealth effects without expenditure data-Or tears: an application to educational enrollments in states of India," Demography, vol. 38, no. 1, pp. 115-132, 2001.

[25] D. R. Gwatkin, S. Rustein, K. Johnson, R. Pande, A. Wagstaff, and A. Amouzou, "Socio-economic differences in health, nutrition, and population in Kenya," The World Bank, 2007.

[26] J. Gregson, S. B. Foerster, R. Orr et al., "System, environmental, and policy changes: using the social-ecological model as a framework for evaluating nutrition education and social marketing programs with low-income audiences," Journal of Nutrition Education and Behavior, vol. 33, supplement 1, pp. S4-S15, 2001.

[27] W. D. Evans, "What social marketing can do for you," British Medical Journal, vol. 332, no. 7551, pp. 1207-1210, 2006.

[28] L. M. Barat, N. Palmer, S. Basu, E. Worrall, K. Hanson, and A. Mills, "Do malaria control interventions reach the poor? A view through the equity lens," American Journal of Tropical Medicine and Hygiene, vol. 71, no. 2, supplement, pp. 174-178, 2004.

[29] A. A. Parker, R. Stephenson, P. L. Riley et al., "Sustained high levels of stored drinking water treatment and retention of hand-washing knowledge in rural Kenyan households following a clinic-based intervention," Epidemiology and Infection, vol. 134, no. 5, pp. 1029-1036, 2006.

[30] E. C. Briere, T. K. Ryman, E. Cartwright et al., "Impact of integration of hygiene kit distribution with routine immunizations on infant vaccine coverage and water treatment and handwashing practices of Kenyan mothers," Journal of Infectious Diseases, vol. 205, supplement 1, pp. S56-S64, 2012.

[31] A. N. Sheth, E. T. Russo, M. Menon et al., "Impact of the integration of water treatment and handwashing incentives with antenatal services on hygiene practices of pregnant women in Malawi," American Journal of Tropical Medicine and Hygiene, vol. 83, no. 6, pp. 1315-1321, 2010.

[32] O. Onwujekwe, E. F. Malik, S. H. Mustafa, and A. Mnzavaa, "Do malaria preventive interventions reach the poor? Socioeconomic inequities in expenditure on and use of mosquito control tools in Sudan," Health Policy and Planning, vol. 21, no. 1, pp. 10-16, 2006.

[33] K. Hanson, T. Marchant, R. Nathan et al., "Household ownership and use of insecticide treated nets among target groups after implementation of a national voucher programme in the United Republic of Tanzania: plausibility study using three annual cross sectional household surveys.," BMJ, vol. 339, article b2434, 2009.

[34] F. Ponsar, M. VanHerp, R. Zachariah et al., "Abolishing user fees for children and pregnant women trebled uptake of malaria-related interventions in Kangaba, Mali," Health Policy and Planning, vol. 26, supplement 2, pp. ii72-ii83, 2011.

[35] J. C. Fotso and B. Kuate-Defo, "Socioeconomic inequalities in early childhood malnutrition and morbidity: modification of the household-level effects by the community SES," Health and Place, vol. 11, no. 3, pp. 205-225, 2005. 


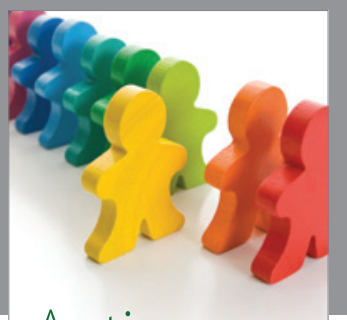

Autism

Research and Treatment
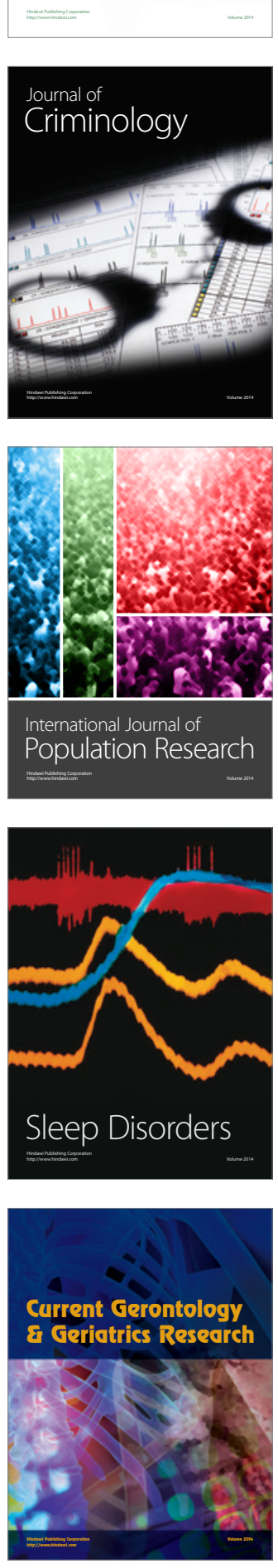
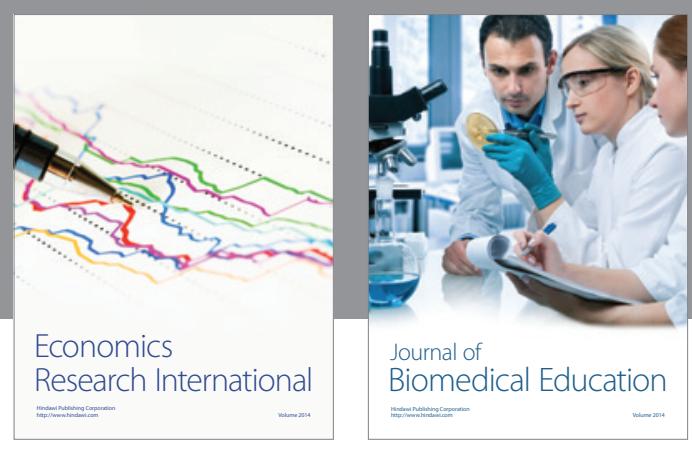

Journal of

Biomedical Education

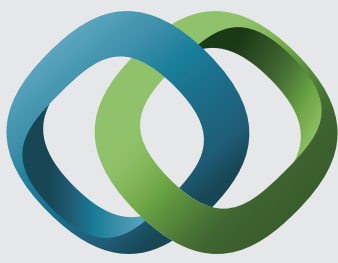

\section{Hindawi}

Submit your manuscripts at

http://www.hindawi.com
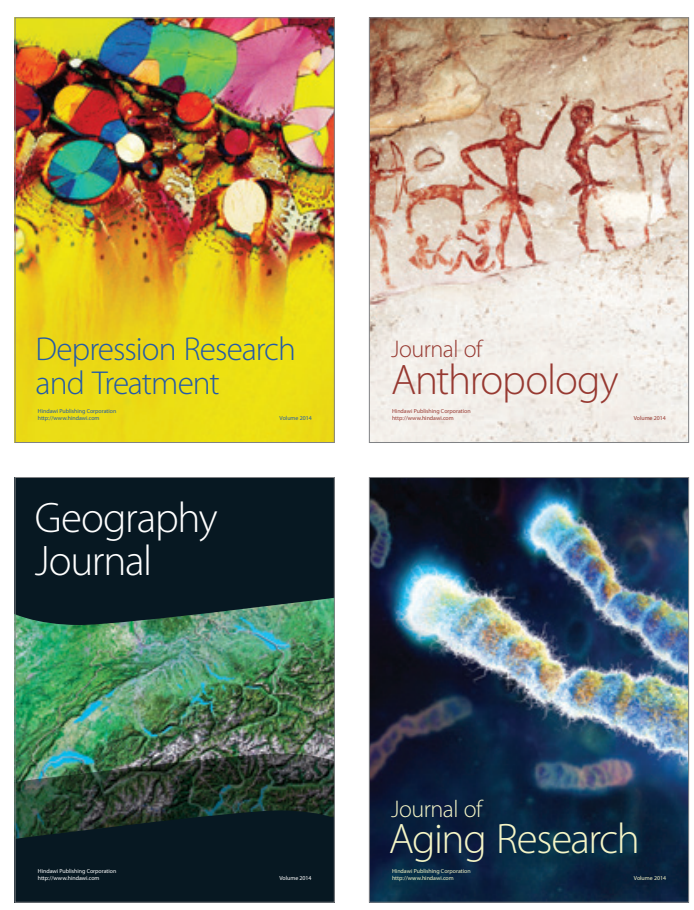

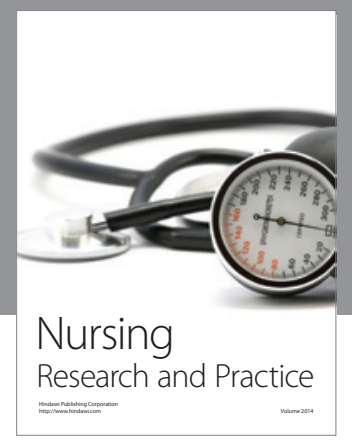

Nursing

Research and Practice

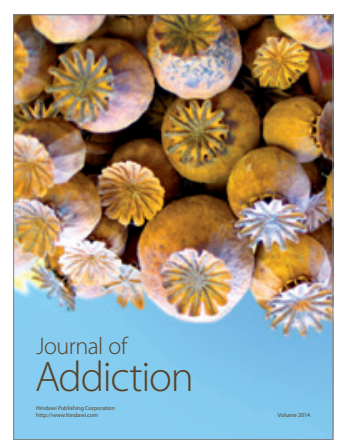

Child Development

Research

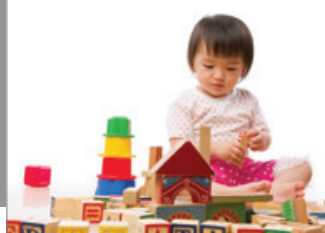

迥
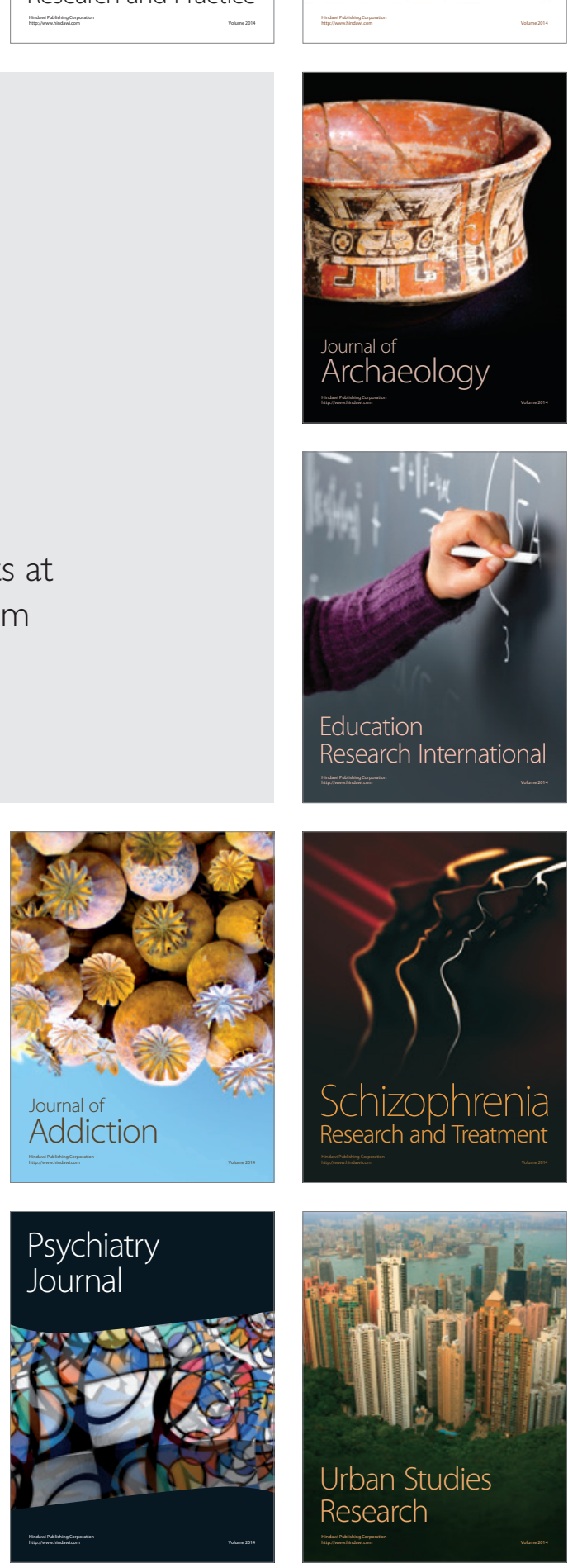